\title{
A systematic literature review of smart grids
}

\author{
Ihor Vakulenko ${ }^{1}$, Liudmyla Saher ${ }^{2 \varpi}$, Oleksii Lyulyov ${ }^{2}$, and Tetyana Pimonenko ${ }^{2}$ \\ ${ }^{1}$ Oleg Balatskyi Department of Management, Academic and Scientific Institute of Business, Economics \\ and Management, Sumy State University, 2, Rymskogo-Korsakova st., 40007 Sumy, Ukraine \\ ${ }^{2}$ Department of Marketing, Academic and Scientific Institute of Business, Economics and \\ Management, Sumy State University, 2, Rymskogo-Korsakova st., 40007 Sumy, Ukraine
}

\begin{abstract}
The development and implementation of smart grids involve developing new and improvements in existing energy technologies, introducing information systems to manage the smart grid, monitoring and controlling energy consumption, and closely related to alternative energy and decarbonization of the economy. Scientific research of smart grids differs significantly in terms of topics because they aim to solve problems in each of these areas. Thus, this research aims to present a bibliometric overview to define the current scientific production state regarding "Smart Grid." A review of 1359 publications from the Scopus database (2008-2020) was conducted. The "Title, abstract, keywords" field of search in the Scopus database was done. The visualization of the results was made using VOSviewer program to map the material graphically. The study used the cooccurrence of keywords and co-authorship (country) analyzes. As a result, the most productive authors and journals were defined. The most cited studies were determined. Country clusters and keywords (co-occurrence) clusters were represented. The obtained results of the analysis and graphical presentations are relevant, and they form the basis for a better understanding of Smart Grid's concept.
\end{abstract}

\section{Introduction}

The development of smart grids is one of the main trends in global energy development. The use of fundamentally new methods in energy and combining them into a holistic, interconnected and independent infrastructure allows to maximize the capabilities of the energy system, implement the principle of distributed energy generation, increase the efficiency of load balancing in the network. In addition, the use of smart technologies in the power grid helps to better meet the needs of consumers.

The global concern about energy issues keeps growing in recent years. Thus, the problems energy efficiency of the country, economic, ecological and energy security is shown by scientists in papers [1-11]. Issues of marketing, communication, environmental management that accompanies the process of building smart grids is discussed in the following studies [12-15]. Issues of sustainable development of society and economy, what are the reason for using smart grids as a means of transition from a traditional energy system to environmentally

\footnotetext{
*Corresponding author: lyudmila.sager@gmail.com
} 
friendly, based on alternative energy, distributed energy production, and intelligent technologies, considered in [16-21].

The authors in the papers [22-33] presented the results of the study of clean energy sources, and ways to convert existing energy networks into renewable ones. The key issues and features of improving the energy efficiency of households are considered in the works [24-25].

The researches [26-32] analyzed current development trends of smart grids, in particular, issues of network management and infrastructure development, the role of users in accelerating / slowing down the pace of smart grids, motivating stakeholders, research on the state of smart grids deployment in the global dimension. The application of information technologies in energy is considered in [33].

Despite the significant work of scientists in the field of smart grids, it is necessary to systematize the directions of their research. This will identify new areas of research, as well as those areas that require further attention of the scientific community. Fundamental and practical approaches to the systematization of scientific knowledge based on the use of advanced tools of bibliometric analysis are studied in the works of [35-38]. Issues of sustainable development of society and economy, what are the reason for using smart grids as a means of transition from a traditional energy system to environmentally friendly, based on alternative energy, distributed energy production, and intelligent technologies, considered in [16-21].

\section{Materials and methods}

For a comprehensive understanding of the research problem and in-depth analysis of the peculiarities of the development of scientific research in this area, a bibliometric analysis was carried out to study the bibliographic material in detail and determine the main scientific directions research area. Bibliometric analysis is an advanced tool for identifying existing "gaps" in the research topic, identifying areas of research that are most relevant and in line with current trends. Bibliometric analysis was performed according to the sequence shown in Table 1.

Table 1. Stages of bibliometric analysis

\begin{tabular}{|c|c|c|c|}
\hline \multicolumn{2}{|r|}{ Stage } & Filters & Result \\
\hline 1 & $\begin{array}{l}\text { Choice of suitable } \\
\text { information sources }\end{array}$ & Scopus database & \\
\hline 2 & $\begin{array}{l}\text { Identification of search } \\
\text { field in the database }\end{array}$ & Title, abstract, keywords & \\
\hline 3 & $\begin{array}{l}\text { Identification of search } \\
\text { keywords }\end{array}$ & Smart grid & 55015 publications \\
\hline 4 & $\begin{array}{l}\text { Identification of } \\
\text { publication type }\end{array}$ & $\begin{array}{l}\text { Journal articles only; conference papers, books, } \\
\text { and chapters of books excluded }\end{array}$ & 16037 publications \\
\hline 5 & Choice of the language & English & 14154 publications \\
\hline 6 & $\begin{array}{l}\text { Choice of the field of } \\
\text { publication }\end{array}$ & $\begin{array}{l}\text { Social Sciences, Business, Management and } \\
\text { Accounting, Economics, Econometrics and } \\
\text { Finance, Decision Sciences }\end{array}$ & 1378 publications \\
\hline 7 & $\begin{array}{l}\text { Identification of the } \\
\text { publications time limits }\end{array}$ & $\begin{array}{l}2008-2020 \text { (since the beginning of the growth } \\
\text { of the number of publications on the subject) }\end{array}$ & 1359 publications \\
\hline 8 & Manual check & $\begin{array}{l}\text { The analysis of the paper in terms of its } \\
\text { relevance }\end{array}$ & 1359 publications \\
\hline
\end{tabular}

The reliability and certainty of bibliometric analysis largely depend on the rating and transparency of information collection sources. Accordingly, one of the most influential and 
authoritative scientific databases, Scopus, was chosen for bibliometric analysis. To study the problem as a keyword was chosen "smart grid," this term is the main one and is officially used to describe the modernization of the energy sector based on intelligent technologies. To ensure the study's complexity and integrity, the search field "title, abstract, keywords" was used.

As the research topic is popular and widely researched, restrictions on selecting relevant materials for bibliometric analysis have been introduced. Thus, only articles written in English were selected for further consideration. Besides, restrictions were introduced on the research field (the focus is on publications that contain an economic component) and the period of publication. Also, the inspection showed that all publications correspond to the research problem. Thus, taking into account all the limitations, 1359 publications were selected for further consideration.

\section{Results and discussions}

Figure 1 shows the dominance of technical publications. In particular, in the field of engineering, informatics, and energy. The share of publications related to economic sectors remains low, but there is a tendency to increase their number.

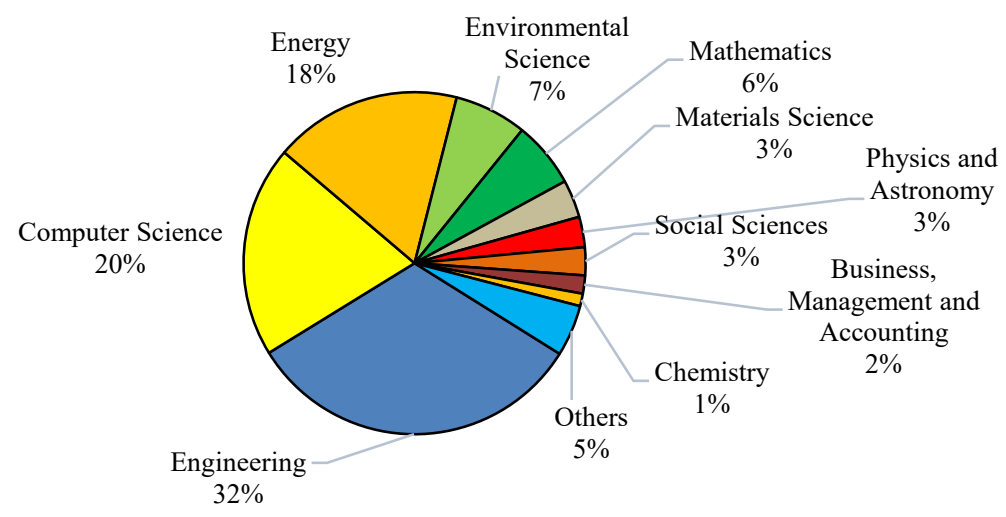

Fig. 1. Publications in the field of smart grids, selected by research areas (based on the Scopus database)

The distribution of scientific works by the studied years is given in Fig. 2. The first publication on the research subject, containing the economic component, dates to 1995 [33], but until 2008 the number of publications did not exceed one per year.

The period of active interest and strengthening of publishing activity in smart grids began in 2008. Since then, there has been a steady trend towards increasing the number of publications (as evidenced by the trend line) with a peak in $2019-245$ publications. Figure 2 also shows over the last five years (from 2016 to 2020), more than $72.3 \%$ of all research materials have been published.

The highest citation rate -2282 - was achieved in 2017 . However, the largest number of citations per publication was in 2009 (81 citations per 1 publication). In 2009, two articles were published, ranking 1st and 3rd among the most cited, respectively.

Analysis of the publications and citations number correlates with trends in the development of smart grids. It allows us to analyze the evolutionary development of research on smart grids. The basis for determining scientific interest is the number of published scientific papers on this topic. Public interest in the subject is determined based on Google Trends, which allows you to track the number of queries related to smart grids in the Google search engine. 
a)

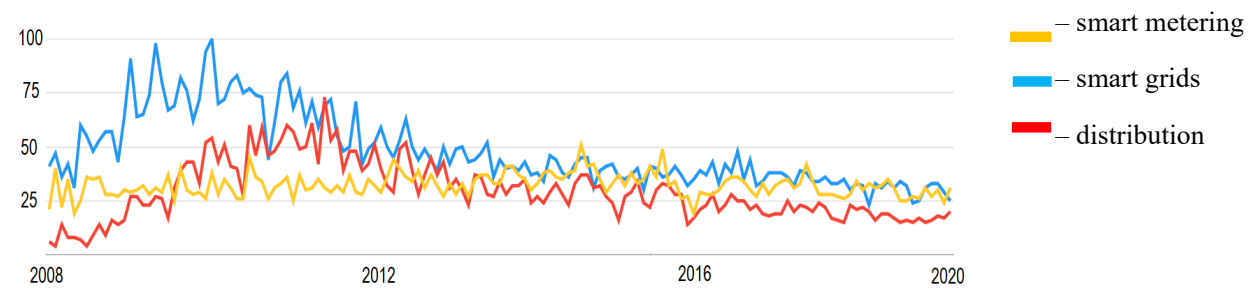

b)

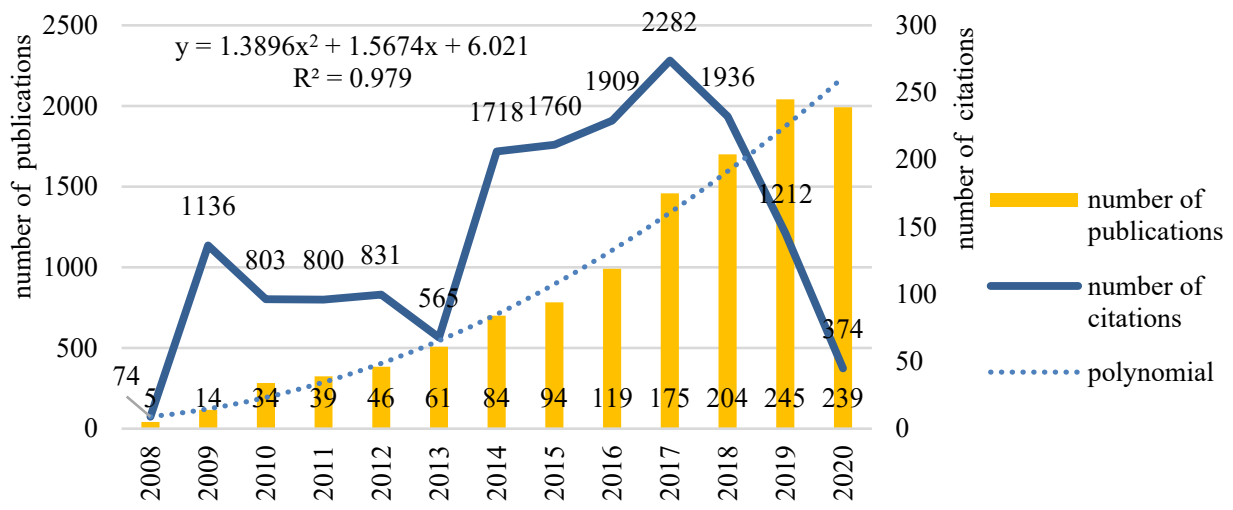

Fig. 2. Comparison of the dynamics of Google search queries on smart grids, smart metering and distributed power generation (a), and scientific publications on smart grids' development, indexed by the database Scopus (b) for 2008-2020.

It is expedient to distinguish four stages in the evolution of scientific and public interest in intelligent power grids. The first stage fell in 2008-2009. This period is characterized by searching for ways to level technical and technological constraints for large-scale implementation of the first stage of smart grid development - forming a basis for full-fledged smart grid projects by deploying smart metering infrastructure. A small number of scientific papers characterizes this period. The shortage of scientific research, which considers the latest technical and technological advances in the development of smart grids, leads to a considerable increase in citations of existing scientific papers. The second stage - 2009-2013 - is the transition from smart metering to the creation of full-featured smart grids. During this period, against the background of the concept's development for introducing smart grids in the energy sector by leading countries (in the introduction of smart grids), researchers focus not on economic but on technical issues of smart grid configuration. The increase in the number of relevant scientific studies is accompanied by an almost twofold decrease in their citations of scientific papers. The results of the analysis in Google Trends show a significant increase in public interest in the topic of smart grids. The third stage - 2014-2017 - is associated with the emergence of new technological constraints in developing smart grids. This period is characterized by a rapid increase in the number of scientific publications and their citation dynamics while reducing public interest in this issue. The fourth stage - from 2017 - is the search for breakthrough technologies that will determine the vector of development of smart grids in the future. During this period, it is worth noting the growing number of scientific papers. Simultaneously, there are multiple reductions of citations of existing developments and also reduction of public interest in this issue due to unresolved technical and technological problems that do not increase smart grid projects 'technical and economic efficiency. It is holding back investment in scaling up smart grids.

To identify existing research trends and identify current areas of further investigation, we analyzed the keywords of publications using VOSviewer, a reliable and effective tool to 
visualize the relationship between the main keywords in research. Three hundred seventeen keywords were selected for analysis (frequency of occurrence more than seven times), after checking the keywords for further consideration, repeated and irrelevant words (for example, "scheduling," "China," and others). A total of 280 keywords were analyzed. Accordingly, the areas of cross-sectoral research of smart grids are shown in Figure 3. Thus, the generated network visualization between 280 keywords includes 6 clusters. The first (most powerful) cluster (red cluster) is formed around the concept of smart grid (the concept establishes 643 connections, the strength of connections -3529 , links -279$)$. This cluster includes the following main keywords: "energy efficiency" (occurrences (occ.) - 98, total link strength 743 , links - 199), "sustainability energy" (occ. -81 , total link strength -607 , links -179 ), "alternative energy" (occ. - 76, total link strength - 584, links - 158), "sustainable development" (occ. - 66, total link strength - 508, links - 175), "renewable energy" (occ. 63 , total link strength -397 , links -148 ), "electricity" (occ. -48 , total link strength -323 , links - 136).

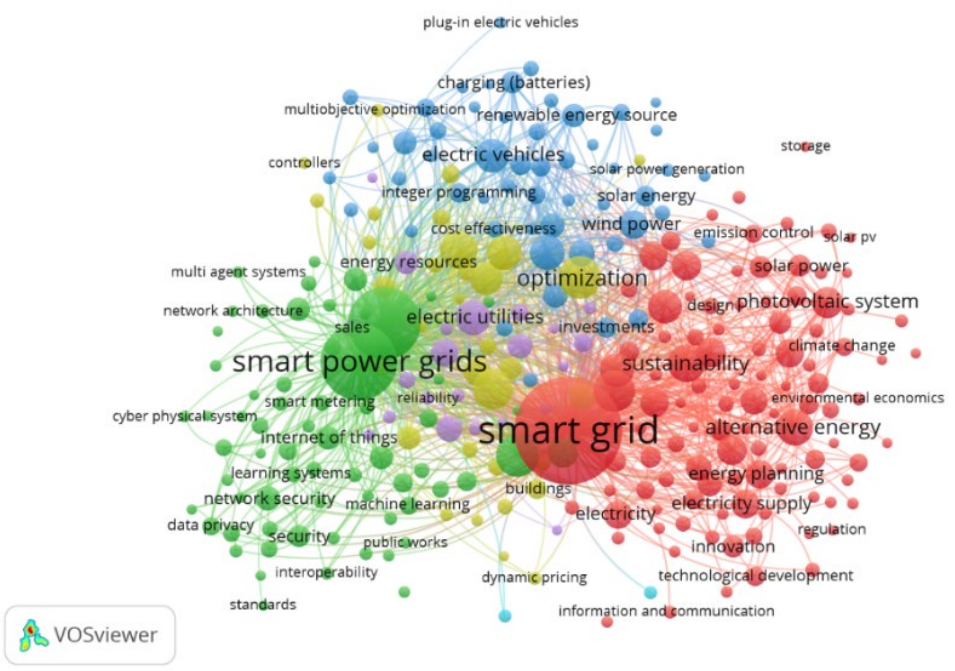

Fig. 3. Identifying areas of cross-sectoral research on smart grids (larger circle diameter means the greater frequency of mention of the concept as a keyword along with smart grids in scientific articles indexed by the scientometric database Scopus for 2008-2020)

The second (green) cluster covers keywords such as "electric power transmission networks" (occ. - 302, total link strength - 2310, links - 255), "smart grids" (occ. - 107, total link strength -570 , links -190 ), "network security" (occ. -34 , total link strength -200 , links - 190), "electric power distribution" (occ. -31 , total link strength -248 , links - 116), "electric power system control" (occ. -31 , total link strength - 239, links - 111), "smart meters" (occ. -32 , total link strength -178 , links -92) and others, and is formed around the concept "smart power grids" (occ. - 331, total link strength - 2388, links - 253).

The third (blue) cluster is tied to the concept "renewable energy resources" (occ.- 73, total link strength -707 , links -73 ) and covers keywords "electric vehicles" (occ. - 64, total link strength -452 , links - 139), "wind power" (occ. -46 , total link strength -333 , links 141), "renewable energy" (occ. - 41, total link strength - 367, links - 142), micro-grid (occ. - 34, total link strength - 339, links - 130), "charging (batteries)" (occ. - 28, total link strength -269 , links -93 ).

At the heart of the fourth (yellow) cluster is the concept "optimization" (occ.- 106, total link strength -813 , links -212 ). The following main keywords belong to this cluster: 
"demand response" (occ. - 90, total link strength - 592, links - 177), "energy management" (occ. -79 , total link strength -629 , links -170 ), "costs" (occ. -72 , total link strength -678 , links - 174), "energy utilization" (occ. -61 , total link strength -541 , links -165 ).

The last fifth (purple) cluster is formed around the concept "electric utilities" (occ. - 28, total link strength - 269, links - 93), it is advisable to include keywords in this cluster "demand-side management" (occ. - 45, total link strength - 355, links - 135), "energy resources" (occ.-32, total link strength - 255, links - 114), "economics" (occ.-35, total link strength -314 , links - 147).

The bibliometric analysis shows that until 2017, research by economists focused mainly on finding ways to commercialize smart grids, including tariff issues. In 2017-2018, the vector of economic analysis of smart grids changed: the focus of scientific attention was on technical and economic optimization of the creation of new and development of existing smart grids projects. In 2018-2019, the emphasis on research was shifted to studying smart grid development's global economic model, their mutual integration, and technical and economic efficiency based on energy consumption patterns (Fig. 4).

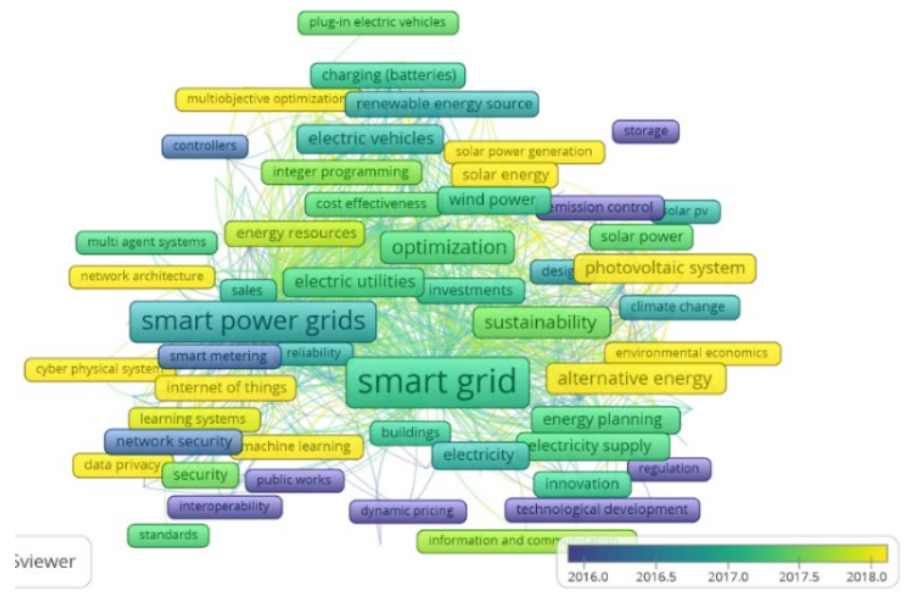

Fig. 4. Visualization map of changing trends in economic research on the development of smart grids, published in 2008-2020 in the publications of the Scopus database

The ten most-cited publications in the "smart grid" in the Scopus database are given in Table 2. All ten articles were cited more than 100 times. The presence of such a tendency to cite indicates that the publications were perceived and highly appreciated by the world scientific community. There is a scientific discussion that emphasizes the relevance of the research topic.

The top 10 most cited publications can be divided into the following research topics: security (items 1,2), renewable energy and sustainable development (items 3, 8), energy efficiency (items 9, 10), micro-networks (items 5), energy management, including pricing, and demand management (items 4, 6, 7).

Thus, the most cited (734 citations) is the publication «Security and privacy challenges in the smart grid» authors - McDaniel P., McLaughlin S. [31]. In this study, the authors considered the state of the spread of smart grids globally and operational, environmental, and financial factors motivating this process in grid security and storage of personal data. In second place is the publication «Smart-grid security issues,» authors Khurana H., Hadley M., Lu N., Frincke D.A. [30], which was cited 392 times. In this publication, the authors have discussed in detail issues related to the security of smart grids. 
The third place is taken by the publication «Cleaner energy for sustainable future» 3 кількістю цитувань 231, автори with citations of 231, authors - Dovì V.G., Friedler F., Huisingh D., Klemeš J.J. [22].

Table 2. Top 10 most cited studies in the field of smart grids from 2008 to 2020 (based on the Scopus database)

\begin{tabular}{|c|c|c|c|c|c|c|}
\hline $\mathrm{No}$ & $\begin{array}{c}\text { Total } \\
\text { citations }\end{array}$ & Article title & Author & $\begin{array}{c}\text { Number of } \\
\text { universities/ } \\
\text { institutions }\end{array}$ & $\begin{array}{l}\text { Number of } \\
\text { countries }\end{array}$ & $\begin{array}{c}\text { Journal/Year of } \\
\text { publication }\end{array}$ \\
\hline 1 & 2 & 3 & 4 & 5 & 6 & 7 \\
\hline 1 & 761 & $\begin{array}{l}\text { Security and privacy } \\
\text { challenges in the smart } \\
\text { grid [31] }\end{array}$ & $\begin{array}{l}\text { McDaniel P., } \\
\text { McLaughlin S. }\end{array}$ & 2 & 1 (USA) & $\begin{array}{l}\text { IEEE Security } \\
\text { and Privacy, } \\
2009 \\
\end{array}$ \\
\hline 2 & 402 & $\begin{array}{l}\text { Smart-grid security issues } \\
{[30]}\end{array}$ & $\begin{array}{c}\text { Khurana H., Hadley } \\
\text { M., Lu N., Frincke } \\
\text { D.A. } \\
\end{array}$ & 4 & 1 (USA) & $\begin{array}{c}\text { IEEE Security } \\
\text { and Privacy, } \\
2010 \\
\end{array}$ \\
\hline 3 & 236 & $\begin{array}{l}\text { Cleaner energy for } \\
\text { sustainable future [22] }\end{array}$ & $\begin{array}{l}\text { Dovì V.G., Friedler } \\
\text { F., Huisingh D., } \\
\text { Klemeš J.J. }\end{array}$ & 4 & $\begin{array}{l}3 \text { (Hungary, } \\
\text { Austria, } \\
\text { Italy) }\end{array}$ & $\begin{array}{c}\text { Journal of } \\
\text { Cleaner } \\
\text { Production, } \\
2009 \\
\end{array}$ \\
\hline 4 & 202 & $\begin{array}{c}\text { The US Department of } \\
\text { Energy's Microgrid } \\
\text { Initiative [32] }\end{array}$ & $\begin{array}{l}\text { Ton D.T., } \\
\text { Smith M.A. }\end{array}$ & 2 & 1 (USA) & $\begin{array}{c}\text { Electricity } \\
\text { Journal, } 2012\end{array}$ \\
\hline 5 & 160 & $\begin{array}{l}\text { Smart grids, smart users? } \\
\text { the role of the user in } \\
\text { demand side management } \\
\text { [29] }\end{array}$ & $\begin{array}{c}\text { Goulden M., } \\
\text { Bedwell B., } \\
\text { Rennick-Egglestone } \\
\text { S., Rodden T., } \\
\text { Spence A. } \\
\end{array}$ & 1 & $\begin{array}{l}1 \text { (Great } \\
\text { Britain) }\end{array}$ & $\begin{array}{c}\text { Energy } \\
\text { Research and } \\
\text { Social Science, } \\
2014\end{array}$ \\
\hline 6 & 118 & $\begin{array}{l}\text { A technical and economic } \\
\text { analysis of one potential } \\
\text { pathway to a } 100 \% \\
\text { renewable energy system } \\
\text { [23] }\end{array}$ & $\begin{array}{l}\text { Connolly D., } \\
\text { Mathiesen B.V. }\end{array}$ & 1 & 1 (Denmark) & $\begin{array}{c}\text { International } \\
\text { Journal of } \\
\text { Sustainable } \\
\text { Energy } \\
\text { Planning and } \\
\text { Management, } \\
2014 \\
\end{array}$ \\
\hline 7 & 117 & $\begin{array}{l}\text { Ten questions concerning } \\
\text { model predictive control } \\
\text { for energy efficient } \\
\text { buildings [24] }\end{array}$ & $\begin{array}{c}\text { Killian M., Kozek } \\
\text { M. }\end{array}$ & 1 & 1 (Austria) & $\begin{array}{l}\text { Building and } \\
\text { Environment, } \\
2016\end{array}$ \\
\hline 8 & 112 & $\begin{array}{l}\text { An unsupervised training } \\
\text { method for non-intrusive } \\
\text { appliance load monitoring } \\
{[25]}\end{array}$ & $\begin{array}{l}\text { Parson O., } \\
\text { Ghosh S., } \\
\text { Weal M., } \\
\text { Rogers A. }\end{array}$ & 4 & $\begin{array}{l}1 \text { (Great } \\
\text { Britain) }\end{array}$ & $\begin{array}{c}\text { Artificial } \\
\text { Intelligence, } \\
2014\end{array}$ \\
\hline
\end{tabular}

The authors who have the most significant number of publications in smart grids in the Scopus database are listed in Table 3.

Thus, the top three authors with the highest publishing activity in the field included Javaid N., Ketter W., Tuite D., Senjyu T. Besides, many articles have been published in leading scientific journals with high SNIP and included in quartiles Q1 and Q2.

The most significant number of citations are published in the journal "Sustainable Cities and Society" (1369), in second place in the number of references is the journal "Journal Of Cleaner Production" (1346), the top three is closed by "Energy Research and Social Science" (1220). The scientific journal "Sustainability" (Switzerland), which has the most publications, is in fourth place in terms of the number of citations (1024 citations). At the same time, per one publication, the most significant number of citations falls on the journal "Energy Research and Social Science" (23.0 citations). 
Table 3. Top authors by the number of publications in the field of smart grids during 2008-2020 (based on the Scopus database)

\begin{tabular}{|c|c|c|}
\hline Author & $\begin{array}{c}\text { Number of published } \\
\text { materials }\end{array}$ & $\begin{array}{c}\text { Author's h-index in the Scopus } \\
\text { database }\end{array}$ \\
\hline Javaid N. & 12 & 41 \\
\hline Ketter W. & 7 & 19 \\
\hline Tuite D. & 7 & 2 \\
\hline Senjyu, T. & 7 & 54 \\
\hline Skjølsvold T.M. & 6 & 9 \\
\hline Afonso J.L. & 5 & 20 \\
\hline Collins J. & 5 & 18 \\
\hline Ryghaug M. & 5 & 14 \\
\hline
\end{tabular}

Particular attention should be paid to the study of geographical coverage in the study of specific issues both in the country and the authors' affiliation (university/institution).

VosViewer toolkit was used to visualize the obtained data. Thus, Fig. 5 presents the relationships between scientists and researchers of smart grids from different countries.

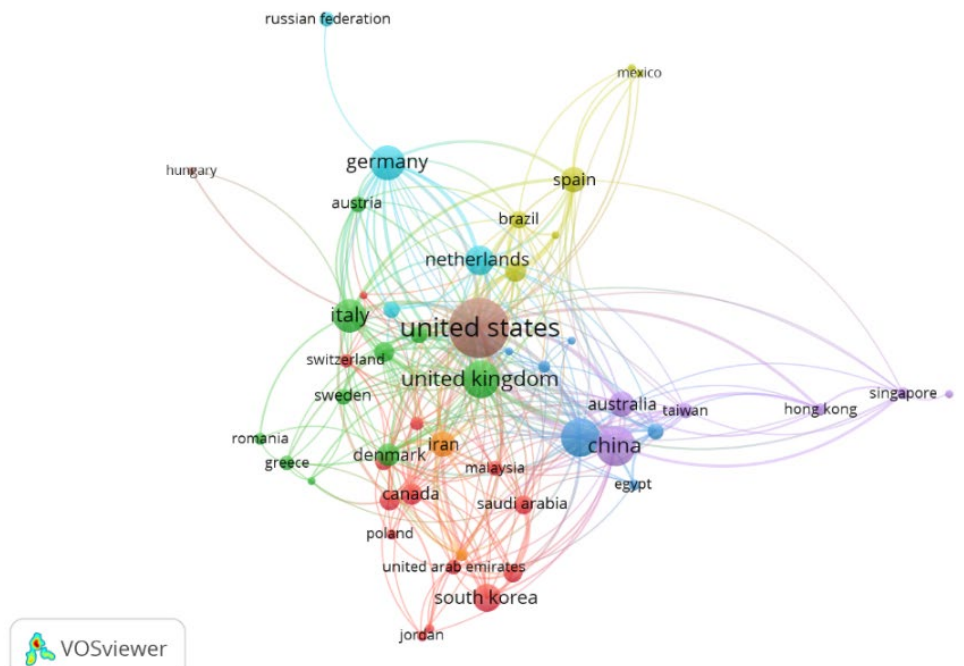

Fig. 5. Visualization map co-authored by scientists (criterion - the country specified in the affiliation), whose joint publications on smart grids were indexed by the Scopus database in 2008-2020

According to the analysis results, eight countries were identified that occupy leading positions in the study. These are USA (277 publications, 5104 citations), China (122 publications, 876 citations), India (117 publications, 500 citations), Great Britain (106 publications, 1823 citations), Germany (89 publications, 860 citations), Italy (85 publications), 1235 citations), the Netherlands (64 publications, 956 citations) and South Korea (63 publications, 424 citations).

Scientists from EU countries have the most significant number of joint publications. In contrast, American researchers' publications are mostly mono-national (prepared without the participation of foreign scientists), although the absolute number of studies by US scientists are undisputed leaders.

An essential step in the analysis of scientific publications is determining the bibliographic relationships related to matches in the lists of references to publications (Fig. 6). This 
bibliographic analysis component is used to determine the relationship between two or more publications when they use references to the same document.

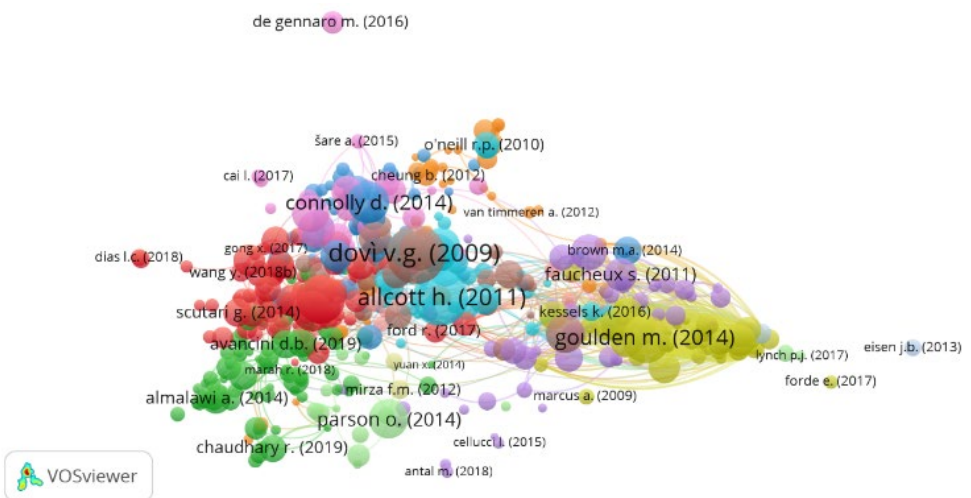

a)

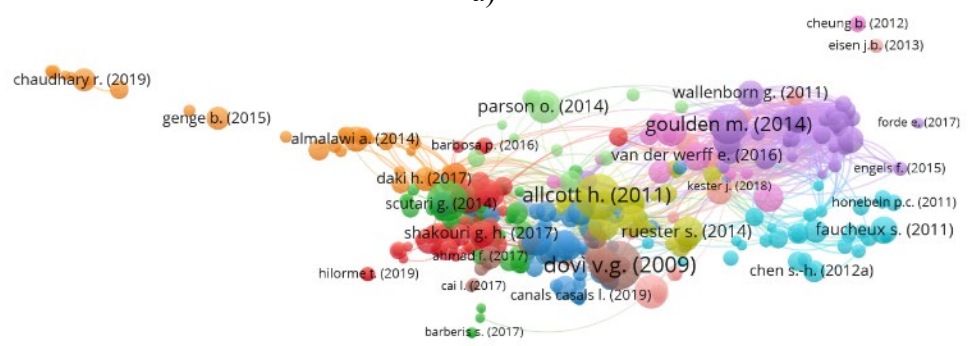

o'neillr.p. (2010)

b)

Fig. 6. Visualization map of bibliographic links of publications on smart grids indexed by the Scopus scientometric database in 2008-2020: a) criterion - 10 mutual citations; b) 5 citations

The nodes' size and color represent the number of links made by the authors of the analyzed articles on the development of smart grids. The analysis shows the strength of the relationship, making it possible to state a significant number of cited links common between the two publications. However, the comparison of these results with those obtained during geographical and evolutionary research on the development of the theory of smart grids and publishing activity on this topic allows us to conclude that scientists' level of cooperation to solve problems of smart grids.

\section{Conclusions}

Thus, our exhaustive analysis of the smart grids that employed a combination of VOSViewer v.1.6.10 and Google Trends allowed more comprehensive and thorough in a formalized by several essential parameters (evolutionary, meaningful, geographical) to generalize the theoretical aspects of the introduction of smart grids in the energy sector.

The analysis presented in this paper creates a basis for further empirical research in the direction of identifying the potential of the smart grids, the interest to the topic and its coverage in the research and scientific literature. In addition, it indicates the prospects and future directions of this area, which can be associated with many unsolved scientific problems 
that hinder the development of smart grids and the formation of an integrated energy-centered model of the economy.

\section{Acknowledgement}

This work was supported by the Ministry of Education and Science of Ukraine (the project No. 0119U100766 "The optimization model of smart and secure energy grids building: an innovative technologies of enterprises and regions ecologisation")

\section{References}

1. S. Kolosok, I. Myroshnychenko, L. Zakharkina, CEUR Workshop Proceedings, 2732, 270-281 (2020)

2. Yu. Harust, V. Melnyk. Marketing and Management of Innovations, 4, 373-382 (2019).

3. Y. Samusevych, A. Vysochyna, T. Vasylieva, S. Lyeonov, S. Pokhylko, E3S Web of Conferences, 234, 00012 (2021)

4. V. Levchenko, A. Boyko, T. Savchenko, V. Bozhenko, Yu. Humenna, R. Pilin, Marketing and Management of Innovations, 4, 364-372 (2019)

5. V. Pavlyk. SocioEconomic Challenges, 4 (1), 122-128 (2020)

6. S. Kolosok, I. Myroshnychenko, H. Mishenina, I. Yarova, E3S Web of Conferences, 234, 00021 (2021)

7. Ye. Ziabina, T. Pimonenko, L. Starchenko, SocioEconomic Challenges, 4 (4), 160-174 (2020)

8. Y. Us, T. Pimonenko, O. Lyulyov, Polityka Energetyczna, 23 (4), 49-66 (2021)

9. V. Panchenko, Yu. Harust, Ya. Us, O. Korobets, V. Pavlyk, Marketing and Management of Innovations, 1, 256-264 (2020)

10. V. Pavlyk, Financial Markets, Institutions and Risks, 4 (1), 117-123 (2020)

11. L. Starchenko, S. Lyeonov, T. Vasylieva, T. Pimonenko, O. Lyulyov, E3S Web of Conferences, 234, 00015 (2021)

12. O. Chygryn, A. Rosokhata, O. Rybina, N. Stoyanets, E3S Web of Conferences, 234, 00004 (2021)

13. R. Boutti, Ad. El. Amri, F. Rodhain, Financial Markets, Institutions and Risks, 3(1), 1829 (2019).

14. N. Letunovska, O. Lyuolyov, T. Pimonenko, V. Aleksandrov, E3S Web of Conferences 234, 00008 (2021)

15. R. Vanickova, Marketing and Management of Innovations, 2, 56-67 (2020)

16. I. Makarenko, N. Sirkovska. Business Ethics and Leadership, 1(1), 16-24 (2017)

17. B. George, Business Ethics and Leadership, 4 (3), 119-126 (2020)

18. E. M. Nelson, SocioEconomic Challenges, 1(3), 116-119 (2017)

19. M. Kostel, D. Leus, A. Cebotarenco, A. Mokrushina, SocioEconomic Challenges, 1 (3), 79-90 (2017)

20. R. Gupta, SocioEconomic Challenges, 1 (1), 81-85 (2017)

21. H. Dave, Financial Markets, Institutions and Risks, 3 (4), 89-93 (2019)

22. V. G. Dovì, F. Friedler, D. Huisingh, J. J. Klemeš, Journal of Cleaner Production, 17(10), 889-895 (2009)

23. D. Connolly, B. V. Mathiesen, International Journal of Sustainable Energy Planning and Management, 1, 7-28 (2014)

24. M. Killian, M. Kozek, Building and Environment, 105, 403-412 (2016)

25. O. Parson, S. Ghosh, M. Weal, A. Rogers. Artificial Intelligence, 217, 1-19 (2014)

26. R. Miskiewicz, Polityka Energetyczna, 21(2), 49-62 (2018) 
27. H. Dzwigoł, M. Dzwigoł-Barosz, Z. Zhyvko, R. Miskiewicz, H. Pushak, Journal of Security and Sustainability Issues, 8(3), 307-317 (2019)

28. I. Vakulenko, L. Saher, L. Syhyda, S. Kolosok, A. Yevdokymova, E3S Web of Conferences, 234, 00020 (2021)

29. M. Goulden, B. Bedwell, S. Rennick-Egglestone, T. Rodden, A. Spence, Energy Research and Social Science, 2, 21-29 (2014)

30. H. Khurana, K. M. Rogers, R. Klump, A. A. Aquino-Lugo, T. J. Overbye, IEEE Transactions on Smart Grid, 1 (1), 40-47 (2010)

31. P. McDaniel, S. McLaughlin, Security and privacy challenges in the smart grid, IEEE Security and Privacy, 7(3), 75-77 (2009)

32. D. T. Ton, M. A. Smith, Electricity Journal, 25 (8), 84-94 (2012)

33. P. Waddell, D. Seraphim, Circuit Design, 12 (3), 1-21 (1995)

34. L. Saher, L. Syhyda, O. Korobets, T. Berezianko, E3S Web of Conferences, 234, 00011 (2021)

35. G. A. Duffy, V. G. Duffy, International Conference on Human-Computer Interaction, 228-241 (2020)

36. A. Zolkover, V. Terziev, Business Ethics and Leadership, 4 (3), 107-118 (2020)

37. T. Vasylieva, V. Kasyanenko, Actual Problems of Economics, 144(6), 50-59 (2013)

38. K. Djalilov, S. Lyeonov, A. Buriak, Financial Markets and Institutions, 5(4CONT1), 178-187 (2015) 